Perspectives on

Complementary

and Alternative

Medicines 
This page intentionally left blank 


\title{
Perspectives on \\ Complementary and Alternative Medicines
}

\author{
Editors \\ Ian Olver
}

Cancer Council Australia and University of Sydney, Australia

Monica Robotin

Cancer Council NSW and University of Sydney, Australia 
Published by

Imperial College Press

57 Shelton Street

Covent Garden

London WC2H 9HE

\section{Distributed by}

World Scientific Publishing Co. Pte. Ltd.

5 Toh Tuck Link, Singapore 596224

USA office: 27 Warren Street, Suite 401-402, Hackensack, NJ 07601

UK office: 57 Shelton Street, Covent Garden, London WC2H 9HE

\section{British Library Cataloguing-in-Publication Data}

A catalogue record for this book is available from the British Library.

\section{PERSPECTIVES ON COMPLEMENTARY AND ALTERNATIVE MEDICINES}

Copyright (C) 2012 by Imperial College Press

All rights reserved. This book, or parts thereof, may not be reproduced in any form or by any means, electronic or mechanical, including photocopying, recording or any information storage and retrieval system now known or to be invented, without written permission from the Publisher.

For photocopying of material in this volume, please pay a copying fee through the Copyright Clearance Center, Inc., 222 Rosewood Drive, Danvers, MA 01923, USA. In this case permission to photocopy is not required from the publisher.

ISBN-13 978-1-84816-556-4

ISBN-10 1-84816-556-0

Typeset by Stallion Press

Email: enquiries@stallionpress.com

Printed in Singapore. 


\section{Contents}

Contributors $\quad x v$

Preface xxi

1 Complementary and Alternative Medicines - The 1 Introductory Perspective

Ian N. Olver

Introduction

What do We Mean by CAM? 3

The Classification of CAM 4

Researching CAM 5

$\begin{array}{ll}\text { Regulation of CAM } & 7\end{array}$

What to Tell the Public about CAM 8

What Medical Practitioners and Students Should 10

Know about CAM

Integrate CAM on What Basis? $\quad 10$

References $\quad 12$

2 Beyond the Classification of Complementary 13 and Alternative Medicine (CAM): Towards a Systematic Approach to Understanding CAM Veronica M. Raszeja

Introduction

Towards the Classification of CAM - A Global and Historical View

Some Examples of Different Systems of CAM

Classification 
Towards a Systematic Approach to Understanding CAM

Conclusion 28

Acknowledgements $\quad 28$

References $\quad 28$

3 Complementary and Alternative Medicine 31 Used by Patients with Cancer: Evidence for Efficacy and Safety

Carlo Pirri

Popular CAM Approaches and Evidence for Use 32

Summary Conclusions $\quad 68$

$\begin{array}{ll}\text { Acknowledgements } & 70\end{array}$

References $\quad 70$

$4 \quad$ The Regulation of Complementary and 89

Alternative Medicine

Ken Harvey

Introduction $\quad 90$

Definitions $\quad 90$

The Regulation of Practitioners $\quad 91$

The Regulation of Products $\quad 92$

Current Controversies and Problems 94

$\begin{array}{ll}\text { Conclusion } & 98\end{array}$

References $\quad 99$

5 Perspective on Chinese Medicine in 103

Complementary and Alternative Medicine

James Flowers

Introduction 104

Applications of Chinese Medicine 106

A Heretical Thought — The Power of God Without God 113

Diagnostic Techniques 117

Conclusion 117

Acknowledgements 118

$\begin{array}{ll}\text { References } & 118\end{array}$ 
6 Disentangling the Evidence: The Efficacy

of Meditation in People with Cancer

Deborah Black, Leigh Wilson and Ramesh Manocha

Introduction

What is Meditation?

122

The Meditation Research Debate

123

The Australian Experience

125

The Extant Evidence

126

Conclusion

136

References

7 Should Spirituality and Prayer be Part of Complementary Therapies?

Ian N. Olver

Spiritual Well-Being

Prayer

Designing Studies of Prayer

Results of a Study of Intercessory Prayer 152

References

8 From Traditional Medicines to Drug Discovery

Monica C. Robotin

Background

Plants in Western Medicine - The Role of

Ethnopharmacology

Using Plants as Sources of Therapeutic Agents

Approaches to Drug Discovery and Development $\quad 165$

Factors Influencing the Contribution of

Ethnomedicine to Drug Development

Some Pros and Cons of Using Plants as Starting

174

Points for a Drug Development Programme

Steps in Moving from Traditional Medicine to

176

Candidate Drug and Beyond

Natural Compounds Currently Used in Cancer Therapy

What is the Future of Natural Medicines in Drug

Discovery?

References 
9 Creating an Integrative Oncology Centre: The

SolarisCare Experience

David Joske

Introduction

188

History and First Steps

Selection of Therapies

Selection of Therapists

Training of Volunteers

Governance and Next Steps

Research and Measuring Efficacy

Minimising Medico-Legal Risk and Medical

Misadventure

SolarisCare Current Structure and Activities

Five Barriers to Complementary Therapy Use in Cancer Care

Recommendations for Sustainability and

Future Research

Conclusions

202

Acknowledgements $\quad 204$

References

10 The Emergence of New Consumerism in

Health-Care: The Empowered Health Consumer and the Role of Complementary and

Alternative Medicine

Liz Paslawsky

Background

208

Changes in the Health-Care Landscape 208

Societal Factors Influencing Consumer Attitudes 215 and Behaviour

Patients Currently Using CAM are Seeking

Something Different to Standard Medical Care

CAM and the Concern of Lack of Disclosure

Policy-Makers, Funders and Health Designers

Conclusion

References 
11 Interaction Between Complementary and

Alternative Medicines and Conventional

Medicines

Stephen J. Clarke and Andrew J. McLachlan

Introduction

228

Mechanisms of CAM-Drug Interactions 229

Conclusion

References

12 Australian Doctors and Complementary

261

Medicine - Don't Ask, Don't Tell and

Don't Know

Lesley Braun

Defining CM - Outside the Scope of Medical 262

Education and Practice?

Integrative Medicine - The New CM 264

What Medical Practitioners Know and Think 265 about CM

Australian GPs' Attitudes and Knowledge about CM 266

Hospital Doctors' Attitudes and Knowledge 268 about CM

Anaesthetists 269

Poor Information Sources Used 270

Knowledge and Communication are Vital 270

Education is Urgently Required 271

Future Implications for Medical Practitioners 272

References $\quad 272$

13 Cancer, Primary Care and Complementary 277

Therapies

Kerryn Phelps

Motivations for Patients Seeking Complementary 279 Therapies

Quality, Safety and Efficacy

Integrative Medicine $\quad 281$

Motivation for Doctors to Develop Expertise in 284

Complementary Therapies 
The Primary Care Team 286

Self-Prescribing $\quad 287$

Access and Affordability 288

References $\quad 289$

14 Complementary and Alternative Medicine: The 291 Perspective of a Medical Oncologist

Ray Lowenthal

Is Everything Natural Harmless? 294

What is Evidence? 295

The Mind-Body Relationship 296

Are Vitamins Harmless? 297

The Immune System and Cancer 298

Diet and Cancer 299

Exotica $\quad 300$

Conclusion 301

The Future 301

References $\quad 302$

15 Complementary and Alternative (or Unproven) 305

Therapies: Perspectives of a Surgeon

Tom Reeve

Introduction $\quad 306$

Comments on Definitions 307

Background from the Diffident Surgeon 307

What Happened before CAM Moved Upmarket? 309

Why Embrace CAM — Are Patients Driving 310

the Agenda?

What CAM Therapies are Available? 312

How are These Modalities Related to Surgical 313

Practice? What Special Skills are Related to

Their Utility for the Surgeon?

Frequently Asked Questions in Relation 314

to CAM

Conclusion

References 
16 Mind over Medicine: Revealing the Blame Game

Deborah Gray

Living the Big Truth $\quad 328$

Soulmate Sisters $\quad 329$

The Goddess Versus the GP 330

The Secret Blame Game 333

17 Barriers to Conducting Complementary and 337

Alternative Medicine Clinical Trials

Byeongsang Oh and Haryana M. Dhillon

Introduction

338

Discrepancies of CAM Definitions $\quad 340$

Diversity of CAM Therapies 341

Discrepancies of Paradigms Between CAM 342 and Conventional Medicine

Lack of Evidence-Based CAM Research

344

Evaluating the Outcome $\quad 345$

Limited Research Funding for CAM Research 347

Ethics Approval for CAM Research 348

Recommendations $\quad 352$

Conclusion 353

References $\quad 353$

18 Teaching Complementary and Alternative 357

Medicines to Medical Students

Craig Hassed

Introduction $\quad 358$

The Definition and Aims of Modern Medicine $\quad 360$

What is Currently Being Taught on CAM? 365

What Should a CAM Curriculum Cover? 366

Conclusion $\quad 369$

References $\quad 369$ 
19 The Consumer Experience - Case Studies of

Complementary Therapy Use Among People

Diagnosed with Cancer

Vivienne O'Callaghan

Obtaining the Stories

374

An Overview of the Respondents and the

Therapies Used

The Experiences of the Women with Breast Cancer

375

The Experiences of People with Other Types of Cancer

Art Therapy

392

Alternative Therapies

393

Conclusion

References

396

20 Evaluating Complementary and Alternative

Medicine

Jaklin A. Eliott

Introduction

400

Defining CAM

401

CAM is Good

404

CAM is Bad

408

Conclusion: CAM is ...

413

References

21 Complementary and Alternative Medicine: The

Perspective of a Cancer Patient

Loretta Marron

Introduction

Alternative Medicines

421

The Growth in Cancer Scams and Scammers

426

The Growth in CAM Products

428

Fighting for Good Information

430

CAM in the Future

Making Informed CAM Choices

Acknowledgements

References 
22 Complementary and Alternative Medicine Use by Adult Cancer Patients: An Overview Carlo Pirri

Introduction

Background

CAM Use by Cancer Patients

Patient-Clinician Communication and

Decision-Making

Efficacy and Safety of CAM 
This page intentionally left blank 


\section{Contributors}

Deborah Black, BSc, Dip Ed, MStat, PhD

Faculty of Health Sciences

The University of Sydney

C42 - Cumberland Campus

Lidcombe, NSW 2141, Australia

Lesley Braun, PhD, BPharm, DipAppSciNaturopathy

Pharmacy Department, Alfred Hospital

Department of Surgery, Monash University

Level 6, The Alfred Centre

99 Commercial Road

Melbourne, VIC 3004, Australia

Stephen J. Clarke, MBBS, PhD, FRACP, FAChPM

Professor of Medicine, The University of Sydney

Senior Staff Specialist in Medical Oncology

Royal North Shore Hospital

Reserve Road

St. Leonards, NSW 2065, Australia

Haryana M. Dhillon, PhD

Post-doctoral Research Fellow

Survivorship Research Group, Centre for Medical Psychology

and Evidence-Based Decision-Making, Central Clinical School

School of Psychology

The University of Sydney 
Brennan MacCallum Building (A18)

Sydney, NSW 2006, Australia

\section{Jaklin A. Eliott, PhD}

Social Scientist, Cancer Council Australia

Affiliate Lecturer, Discipline of Public Health

The University of Adelaide

Level 11, 178 North Tce

Adelaide, SA 5005, Australia

James Flowers, MA

Department of Medical History

College of Oriental Medicine

Wonkwang University

344-2 Shinyongdong

Iksan, Chonbuk, Korea

\section{Deborah Gray}

Author and Broadcaster

DeborahGrayMagic

P.O. Box 229

Woollahra, NSW 2025, Australia

Ken Harvey, MBBS, FRCPA

Adjunct Senior Lecturer

School of Public Health

La Trobe University

Medreach Pty. Ltd.

35a Mary St.

Hawthorn, VIC 3122, Australia

Craig Hassed, MBBS, FRACGP

Senior Lecturer

Deputy Head, Department of General Practice

School of Primary Health Care

Faculty of Medicine, Nursing and Health Sciences

Monash University

Bldg 1, 270 Ferntree Gully Rd

Notting Hill, VIC 3168, Australia 


\section{David Joske, MBBS, FRACP, FRCPA}

Founder and Chairman, SolarisCare Foundation Cancer Support Centres

Clinical Professor of Medicine, University of Western Australia Head, Department of Haematology

Sir Charles Gairdner Hospital

Hospital Avenue

Nedlands, WA 6009, Australia

\section{Ray Lowenthal, AO, MBBS, MD, FRCP, FRACP, FAChPM}

Consultant Haematologist/Oncologist, Royal Hobart Hospital Honorary Member, Menzies Research Institute

Clinical Professor, Faculty of Health Science

School of Medicine, University of Tasmania

Hobart CBD Campuses

Medical Science 1, Private Bag 68

Hobart, TAS 7001, Australia

Ramesh Manocha, MBBS, BSc(Med), PhD

Senior Lecturer, Discipline of Psychiatry

Sydney Medical School

The University of Sydney

Edward Ford Building A27

Sydney, NSW 2006, Australia

\section{Loretta Marron, BSc, Assoc Dip Bus(Accnt), AAII, MACS}

Cancer Survivor and Author

Email: health.info@bigpond.com

\section{Andrew J. McLachlan, Bpharm, PhD, FPS, FACP, MCPA, MSHPA}

Professor of Pharmacy (Aged Care)

Faculty of Pharmacy and Centre for Education and

Research on Ageing

The University of Sydney and Concord Hospital

A15 Science Rd

Sydney, NSW 2006, Australia 


\section{Vivienne O'Callaghan, BA, BHlthSc(ComplMed)}

Publications Editor

Cancer Council New South Wales

153 Dowling Street

Woolloomooloo, NSW 2011, Australia

\section{Byeongsang $\mathrm{Oh}, \mathrm{PhD}$}

Clinical Senior Lecturer, Sydney Medical School

The University of Sydney

Edward Ford Building A27

Sydney, NSW 2006, Australia

\section{Ian N. Olver, AM, MD, PhD}

Clinical Professor, Sydney Medical School

The University of Sydney

$\mathrm{CEO}$, Cancer Council Australia

120 Chalmers Street, Surry Hills

New South Wales 2010, GPO Box 4708

Sydney, NSW 2001, Australia

\section{Liz Paslawsky, PhD, MHA, BSc(Hons1)}

International Health Business Consultant

G11/1 Clement Place

Rushcutters Bay, 2011 NSW, Australia

Kerryn Phelps, AM, MBBS (Syd), FRACGP, FAMA

President, Australasian Integrative Medicine Association

Conjoint Professor, University of New South Wales

Adjunct Professor, Sydney Medical School

c/o Cooper Street Clinic

1a Cooper St

Double Bay, NSW 2028, Australia

\section{Carlo Pirri, BSc, BPsych, MPsych(Clinical)}

Research and Statistical Consultant / PhD Candidate

Faculty of Health Sciences (Psychology)

Murdoch University

90 South Street

Murdoch, WA 6150, Australia 
Veronica M. Raszeja, BA(Hons), GradDipPsych

M.Phil.(Medicine) Candidate at the Centre for Values,

Ethics and the Law in Medicine

The University of Sydney

Level 1, Medical Foundation Building

92-94 Parramatta Road

Camperdown, NSW, Australia

\section{Tom Reeve, AC, CBE}

Emeritus Consultant in Surgery, Royal North Shore Hospital

Emeritus Professor of Surgery, Sydney Medical School

The University of Sydney

Edward Ford Building A27

Sydney, NSW 2006, Australia

Monica C. Robotin, MBBS, FRACS, MBA, A Appl Epid, M Int Health

Medical Director, Cancer Council New South Wales

Senior Lecturer, School of Public Health

The University of Sydney School of Medicine

Kings Cross, NSW 1340

Sydney 2011, Australia

Leigh Wilson, MPH, Grad Cert Clin Res Mgmt, DPH

Faculty of Health Sciences

The University of Sydney

C42 - Cumberland Campus

Lidcombe, NSW 2141, Australia 
This page intentionally left blank 


\section{Preface}

The subject of complementary and alternative medicines attracts controversy. There is often great passion expressed by proponents of both conventional and complementary and alternative therapies.

The current paradigm in "Western" medicine is that it must be evidence-based. There are established scientific methodologies, epitomised by the randomised controlled trial, which govern the investigation of new treatments. The results of this research are used by practitioners to balance the known risks and benefits when advising patients about treatment options.

In contrast, the principles of Chinese medicine, for example, are part of a culture that has evolved over centuries and belief in that system is part of the healing experience. Other complementary and alternative medicines are promoted through collections of single case reports.

Central to the discussion of any treatment is the patients. Patients differ widely in their understanding of evidence-based medicine, and for them there is a singular personal experience of illness. They receive information from multiple sources, including friends and relatives, and weigh many factors, beyond the medical facts, into treatment decisions. They use complementary and alternative therapies to a similar degree as conventional medicines. They often seek to maintain control over their therapy. If they feel that their doctor disapproves of a complementary or alternative medicine choice they simply do not discuss it and therefore never receive the doctor's perspective. They can be left with a confusing array of opinions. 
My co-editor, Monica Robotin from Cancer Council New South Wales, joined with me at Cancer Council Australia to collect together a broad spectrum of perspectives on complementary and alternative medicines. We chose authors who practised complementary and alternative medicine, those who practised conventional medicine, researchers, educators and consumers. We asked each to present their perspective on complementary and alternative medicines, and gave them the freedom to express themselves in their own styles. The result is a lively mixture of poignant stories, strong opinions and scientific reviews. By reading 20 different perspectives on complementary and alternative medicines we trust that readers will then be able to form their own opinions, their perspectives.

We are most grateful that all the authors agreed to give their time and expertise voluntarily, and indeed the proceeds will go towards cancer control and support activities at the Cancer Councils. It also reflects a passion that we all share for improving the lives of those with cancer. 